\title{
Dose inseminante para fertilização artificial de ovócitos de dourado
}

\author{
Eduardo Antônio Sanches ${ }^{1 *}$, Robie Allan Bombardelli², Diego Mendes Baggio², Bruno \\ Estevão de Souza ${ }^{3}$
}

\footnotetext{
${ }^{1}$ Pós-Graduação, Centro de Aqüicultura da Universidade Estadual Paulista Julio de Mesquita Filho, Jaboticabal, SP

${ }^{2}$ Curso de Engenharia de Pesca da Universidade Estadual do Oeste do Paraná, Toledo, PR.

${ }^{3}$ Instituto Federal do Paraná, Foz do Iguaçu, PR.
}

\begin{abstract}
RESUMO - Objetivou-se determinar a dose inseminante adequada para uso na fertilização artificial de ovócitos de dourado (Salminus brasiliensis). Os ovócitos foram distribuídos em delineamento inteiramente casualizado, e fertilizados com uma das relações espermatozoides/ovócito $6,0 \times 10^{3} ; 6,0 \times 10^{4} ; 6,0 \times 10^{5} ; 6,0 \times 10^{6}$ ou $3,0 \times 10^{7}$, cada uma com quatro repetições Considerou-se unidade experimental uma incubadora de volume útil de 2,5 L, contendo 2,0 mL de ovócitos não-hidratados. As taxas de fertilização foram mensuradas 8 horas após o início da fertilização. Com intuito de verificar possíveis efeitos da diluição seminal na movimentação dos espermatozoides, realizou-se a mensuração do tempo de duração da motilidade espermática dos espermatozoides de dourado, ativados por meio de diferentes relações de diluição: $6,8 \times 10^{-5}$; $6,8 \times 10^{-4}$; $6,8 \times 10^{-3} ; 6,8 \times 10^{-2} ; 3,4 \times 10^{-1}$ e $1,0 \mathrm{~mL}$ de sêmen por $\mathrm{mL}$ de água. O tempo de duração da motilidade foi avaliado em delineamento inteiramente casualizado composto de seis tratamentos e três repetições. As taxas de fertilização apresentaram relação quadrática com o número de espermatozoides por ovócito. As relações de diluição do sêmen tiveram efeito inversamente proporcional sobre a duração da motilidade espermática. A relação que proporcionou melhores taxas de fertilização artificial de ovócitos de dourado (Salminus brasiliensis) foi de 30.722 espermatozoides por ovócio.
\end{abstract}

Palavras-chave: espermatozoide/ovócito, inseminação artificial, peixes, reprodução, Salmininae, Salminus brasiliensis, sêmen

\section{Insemination dose for artificial fertilization of dourado oocytes}

\begin{abstract}
The objective of the present study was to determine the proper insemination dose of dourado (Salminus brasiliensis) oocytes. The oocytes were placed in a randomized complete design and fertilized with one of the spermatozoa.oocytes ${ }^{-1}$ ratio, $6.0 \times 10^{3}, 6.0 \times 10^{4}, 6.0 \times 10^{5}, 6.0 \times 10^{6}, 3.0 \times 10^{7} \mathrm{SPZ}$ :OOC, each one with four replications. An experimental unit was considered to be an incubator with a $2.5 \mathrm{~L}$ useful volume containing $2.0 \mathrm{~mL}$ non-hydrated oocytes. The fertilization rates were measured eight hours after the start of fertilization. In order to ascertain the possible effects of seminal dilution on the spermatozoa motility, the duration time of the spermatic motility of the dourado spermatozoa was measured when activated by different dilution ratios $6.8 \times 10^{-5} ; 6.8 \times 10^{-4} ; 6.8 \times 10^{-3} ; 6.8 \times 10^{-2} ; 3.4 \times 10^{-1}$ and $1.0 \mathrm{~mL}$ semen.mL water ${ }^{-1}$. The motility duration time was assessed in a randomized complete design, with six treatments and three repetitions. The fertilization rates showed a quadratic relationship with the number of spermatozoids per oocyte. The semen dilution ratios had an inversely proportional affect on the spermatic motility time. The spermatozoa:oocytes ratio that provided the best artificial fertilization rates of dourado (Salminus brasiliensis) oocytes was 30,722 spermatoids per oocyte.
\end{abstract}

Key Words: artificial insemination, fish, reproduction, Salmininae, Salminus brasiliensis, semen, spermatozoa/oocytes

\section{Introdução}

O dourado (Salminus brasiliensis, Cuvier, 1817) é uma espécie de peixe da família Characidae, subfamília Salmininae e gênero Salminus (Nakatani et al., 2001), nativa de algumas bacias hidrográficas da América do Sul (Froese \& Pauly, 2007). Apresenta grande potencial para a piscicultura brasileira, por seu rápido desenvolvimento inicial e elevado preço de mercado (Weingartner \& Zaniboni Filho, 2005).

Apesar de a tecnologia da reprodução artificial de peixes nativos brasileiros se encontrar relativamente desenvolvida (Zaniboni Filho \& Weingartner, 2007), o estudo de alguns aspectos relacionados à otimização do uso dos reprodutores ainda deve ser realizado (Godinho, 2007), especialmente para avaliação da qualidade dos

Este artigo foi recebido em 18/7/2008 e aprovado em 10/12/2008. 
gametas masculinos e femininos (Rizzo et al., 2003; Rurangwa et al., 2004; Alavi \& Cosson, 2005), dos métodos adequados de fertilização artificial (Suquet et al., 1995) e do emprego de métodos de conservação dos gametas (Carolsfeld et al., 2003).

A qualidade dos gametas e os métodos de fertilização artificial têm sido frequentemente avaliados, principalmente por meio de parâmetros que influenciam diretamente as taxas de fertilização, como duração da motilidade espermática (Tvedt et al., 2001), relação espermatozoide:ovócito (Bombardelli et al., 2006a) e diluição empregada no material fertilizante (Lahnsteiner et al., 2003). Esses parâmetros, quando manejados corretamente, melhoram significativamente as taxas de fertilização (Chereguini et al., 1999).

Conhecer o número adequado de espermatozóides por ovocito é fundamental na rotina de reprodução artificial de peixes, pois esse conhecimento, além de influenciar as taxas de fertilização (Bombardelli et al., 2006a), revela a possibilidade de limitar o estoque de machos na piscicultura intensiva, propiciando exploração mais racional de reprodutores geneticamente selecionados e redução nos custos de produção (Fogli da Silveira et al., 1988). O conhecimento da dose inseminante adequada também é importante para o desenvolvimento de programas de criopreservação de sêmen e/ou ovócitos, destinados tanto à conservação da biodiversidade genética de espécies como a programas de melhoramento genético em fazendas de cultivo (Denniston et al., 2000).

Assim, realizou-se este estudo com o objetivo de determinar a dose inseminante adequada para uso na fertilização artificial de ovócitos de dourado (S. brasiliensis).

\section{Material e Métodos}

O experimento foi conduzido no Laboratório de Tecnologia da Reprodução de Animais Aquáticos Cultiváveis/UNIOESTE, instalado no Centro de Pesquisas em Aqüicultura Ambiental (CPAA/IAP), em Toledo, Paraná. Foram utilizados 20 reprodutores de dourado (S. brasiliensis), 15 machos e 5 fêmeas, provenientes da própria estação de pesquisa. Foram selecionados, dentro dos tanques de cultivo, machos que liberavam esperma sob leve pressão abdominal, realizada por massagem no sentido céfalo-caudal, e fêmeas com o ventre arredondado, papila genital saliente e com coloração rosada. Para certificar o estágio de maturação gonadal das fêmeas, foram realizadas biópsias ovarianas. Os ovócitos retirados foram submetidos à solução de Serra (Woynarovich \& Horváth, 1983) e visualizados em lupa com aumento de quatro vezes, para avaliação da migração da vesícula germinativa(Stoeckel, 2000). Depois dessa avaliação, foram selecionadas apenas as fêmeas com mais de $80 \%$ dos ovócitos com vesícula germinativa polarizada.

Os animais selecionados foram individualmente pesados, medidos e marcados e posteriormente separados por sexo em caixas circulares com renovação constante por meio de bombeamento de água proveniente de um tanque da própria estação.

Com intuito de obter grande quantidade de sêmen e promover a maturação final dos ovócitos, foram aplicadas duas doses de extrato pituitário de carpa (EPC), de modo que machos e fêmeas receberam um total de $5,5 \mathrm{mg}$ de EPC.kg de reprodutor ${ }^{-1}$. Desse total, a primeira dose foi correspondente a $10 \%$ do total e realizada 12 horas antes da segunda, conforme descrito por Weingartner \& Zaniboni Filho (2005). As aplicações foram realizadas de forma intraperitonial, na região da nadadeira peitoral. Após as aplicações, a temperatura da água foi monitorada frequentemente.

A coleta dos gametas, tanto masculinos quanto femininos, foi realizada após 140 horas - grau (unidades térmicas acumuladas - UTA). Os gametas foram contados a partir da segunda aplicação hormonal, respeitando a ordem de coleta (primeiro os gametas masculinos e posteriormente os femininos), no intuito de evitar a perda de viabilidade dos ovócitos após a coleta.

Após a mensuração do volume total de sêmen liberado por meio de um tubo de ensaio graduado, os gametas masculinos coletados foram posteriormente colocados em pequenos recipientes em caixas de isopor contendo gelo (Marques \& Godinho, 2004) e conservados a temperatura média de $13{ }^{\circ} \mathrm{C}$. Em seguida, foi realizada a mistura do sêmen proveniente de todos os reprodutores, originando um pool de sêmen. Em seguida, foram feitas análises da concentração espermática (espermatozoides/mL), do índice de alterações morfológicas dos espermatozoides (\%), do índice de sobrevivência espermática (\%) e do tempo de duração da motilidade espermática (segundos, s).

A mensuração da concentração espermática do sêmen foi realizada pelo método da contagem de células espermáticas (Streit Jr. et al., 2004a), em câmara hematimétrica de Neubauer (Wirtz \& Steinmann, 2006). Para mensuração da concentração espermática, utilizou-se uma amostra de $3 \mu \mathrm{L}$ do sêmen, que foi diluída em $3000 \mu \mathrm{L}$ de formol salina tamponado, resultando numa diluição de 1:1000 (Streit Jr. et al., 2004b). Do mesmo material obtido anteriormente, foram realizados dois esfregaços para avaliação e mensuração do índice de alterações morfológicas 
dos espermatozoides (Streit Jr. et al., 2006). As lâminas foram submetidas à coloração em rosa bengala (Streit Jr. et al., 2004b) e analisadas em microscópio de luz e objetiva de 40×, avaliando-se um número total de 400 espermatozoides.

O índice de sobrevivência espermática foi mensurado pelo método de coloração eosina-nigrosina (Murgas et al., 2003), porém com $30 \mu \mathrm{L}$ de sêmen e $90 \mu \mathrm{L}$ de cada corante, para realização de uma mistura e confecção do esfregaço. Após o processamento das lâminas, o material foi analisado em microscópio de luz em objetiva de $40 \times$, contando-se um número total de 400 espermatozoides, no qual células mortas apresentaram-se rosadas, em decorrência da absorção dos corantes, e as vivas apresentaram-se brancas, por serem impermeáveis aos corantes.

O tempo de duração da motilidade espermática foi mensurado utilizando-se $5 \mu \mathrm{L}$ de sêmen, diluídos em $200 \mu \mathrm{L}$ de solução ativadora (água) a $28^{\circ} \mathrm{C}$, resultado em diluição sêmen/água de 0,025. Após a diluição, utilizaram-se $5 \mu \mathrm{L}$ da mistura para avaliação em microscópio de luz (40×) do tempo em que aproximadamente $50 \%$ dos espermatozoides se mantiveram móveis.

Os ovócitos liberados foram coletados em placas de petri e, para evitar possíveis contaminações com urina e sangue, as porções de ovócitos liberadas com esses fluidos foram descartadas. Após a coleta dos gametas masculinos e femininos, foi determinado o número relativo de ovócitos não-hidratados por mL, pela contagem de três amostras de 0,1 mL de ovócitos. Em seguida, foram coletadas separadamente 20 amostras de $2 \mathrm{~mL}$ de ovócitos não-hidratados, para realização dos ensaios de fertilização. As doses inseminantes foram determinadas com base na concentração espermática do pool de sêmen e as dosagens seminais realizadas com micropipetas de volume variável.

Assim, foram utilizados $40 \mathrm{~mL}$ de ovócitos nãohidratados, os quais foram misturados ao sêmen, fertilizados e distribuídos em 20 incubadoras experimentais confeccionadas em PVC, com formato cônico e de volume útil de 2,5 L. Os ovócitos fertilizados foram distribuídos em delineamento experimental inteiramente casualizado, composto de cinco tratamentos e quatro repetições. Os tratamentos foram constituídos pelas doses inseminantes ou relações de número de espermatozoides por ovócito: $6 \times 10^{3} ; 6 \times 10^{4} ; 6 \times 10^{5} ; 6 \times 10^{6}$ ou $3 \times 10^{7}$ espermatozoides/ ovócito. Como unidade experimental utilizou-se uma incubadora de volumeútil de 2,5L, contendo 2,0 mL de ovócitos não-hidratados (2.160 ovócitos), posteriormente fertilizados.

Para ativação dos gametas, utilizaram-se $25 \mathrm{~mL}$ de solução ativadora (água), proveniente do próprio sistema de incubação a $28{ }^{\circ} \mathrm{C}$ em cada unidade experimental. A fertilização foi realizada em copos plásticos de volume útil de $150 \mathrm{~mL}$ e agitados por aproximadamente um minuto. A partir daí, os ovos foram hidratados e posteriormente transferidos para as unidades experimentais.

Após a fertilização, a água das incubadoras foi mantida aquecida a $28 \pm 1^{\circ} \mathrm{C}$ a partir de um sistema de aquecimento de água com resistência elétrica e termostato. A taxa de fertilização foi mensurada 8 horas após o início da hidratação dos ovos utilizando-se três amostras de aproximadamente 260 ovos de cada unidade experimental.

Considerando que o volume de sêmen utilizado para a fertilização variou entre as relações espermatozoides/ ovócito avaliadas e que o volume de solução ativadora foi constante, determinou-se ainda o tempo de duração da motilidade espermática em sêmen submetido a diferentes relações de diluição entre o sêmen e a solução ativadora. Neste caso as relações de diluição empregadas foram as mesmas do ensaio de fertilização mais a relação de $1 \mathrm{~mL}$ de sêmen por $\mathrm{mL}$ de água. Esse procedimento foi realizado para verificar o possível efeito dessa condição sobre a fertilização artificial dos ovócitos.

No ensaio de avaliação do tempo de duração da motilidade espermática, utilizou-se um delineamento experimental inteiramente casualizado, composto de seis relações de diluição $\left(6,8 \times 10^{-5} ; 6,8 \times 10^{-4} ; 6,8 \times 10^{-3} ; 6,8 \times 10^{-2}\right.$; $3,4 \times 10^{-1}$; e 1,0 mL de sêmen/mL de água) e três repetições. Nos ensaios, as diluições foram realizadas em copos plásticos de volume útil de 150,0 mL, de modo que o volume de água utilizado foi mensurado em pipetas volumétricas de precisão $0,1 \mathrm{~mL}$ e o sêmen dosado em micropipetas de volume variável. O sêmen utilizado neste ensaio foi proveniente de outro lote de reprodutores não-utilizados no ensaio de fertilização.

Os resultados das taxas de fertilização e do tempo de duração da motilidade espermática foram submetidos à análise de variância a 5\% de significância e, em caso de diferença significativa, foi aplicada a análise de regressão, também a 5\% de significância. O software utilizado para a realização das análises estatísticas foi o SAEG (Sistema de Análises Estatísticas e Genéticas) (UFV, 1997).

\section{Resultados e Discussão}

O volume de sêmen observado no dourado (Tabela 1), assim como em outras espécies de peixes brasileiras, apresentou diferenças interespecíficas (Andrade-Talmelli et al., 2001; Ninhaus-Silveira et al., 2006; Bombardelli et al., 2006a), no entanto, essas variações podem ocorrer de acordo com o método de colheita, uma vez que a extrusão não garante a liberação total do sêmen presente nas gônadas (Ferreira et al., 2001). 
Assim como o volume seminal, a concentração espermática também apresenta variações (Maria et al., 2004; Murgas et al., 2004; Murgas et al., 2007; Godinho, 2007). No entanto, essas variações podem ser influenciadas por fatores como tamanho do indivíduo (Luz et al., 2001), idade dos reprodutores (Bastardo et al., 2004), coletas seminais sucessivas (Kavamoto et al., 1997), indução hormonal (Kavamoto \& Fogli da Silveira, 1986), hormônios aplicados durante o processo de indução hormonal (Streit Jr. et al., 2003; Bombardelli et al., 2006b), época do ano (Borges et al., 2005) e metodologia de coleta (Ferreira et al., 2001).

O índice de sobrevivência espermática determinado para os espermatozoides de dourado neste experimento (Tabela 1) foi semelhante ao encontrado para outras espécies (Fogli da Silveira et al., 1990; Bombardelli et al., 2006a; Souza, 2007). Espermatozoides de boa qualidade são aqueles com índices superiores a 50\% de sobrevivência (Bastardo et al., 2004). O conhecimento dessa variável é fundamental para estudos relacionados à qualidade seminal de peixes, pois esses valores podem interferir diretamente no percentual de motilidade espermática e posteriormente nas taxas de fertilização de ovócitos.

A duração da motilidade dos espermatozoides de dourado verificada neste experimento (Tabela 1) foi semelhante à registrada em outras espécies. No entanto, essas avaliações apresentam algumas divergências, pois alguns autores realizam estas mensurações considerando o tempo necessário para a perda de motilidade de 100\% dos espermatozoides (Streit Jr. et al., 2006), enquanto outros autores consideram apenas o tempo necessário para a perda da motilidade de aproximadamente $50 \%$ (Bombardelli et al., 2006c; Hilbig et al., 2008) ou 90\% (Murgas et al., 2004) dos espermatozoides. Assim, a falta de padronização dos métodos de avaliação impede a comparação dos resultados.

Da mesma forma à da concentração espermática e à da produção seminal, o tempo de duração da motilidade espermática também é afetado por fatores como as soluções ativadoras (Carolsfeld et al., 2003), as relações de diluição do sêmen (Lahnsteiner et al., 2003), as concentrações osmóticas e iônicas (Alavi \& Cosson, 2006) e as temperaturas das soluções ativadores (Alavi \& Cosson, 2005).

Nas análises do índice de alterações morfológicas dos espermatozoides utilizados no ensaio de fertilização, $35,5 \%$ dos espermatozoides apresentaram-se normais, 27,7\% com alterações primárias e 36,8\% com alterações secundárias. Apesar de alguns estudos relatarem as análises de morfologia espermática em peixes (Bombardelli et al., 2006a; Streit Jr. et al., 2006), ainda falta a definição do índice de anormalidade aceitável aos reprodutores em estações comerciais de cultivo. Em mamíferos, animais com índices de anormalidade espermática superiores a 30\% são considerados inadequados para o uso em fertilização artificial ou monta natural (CBRA, 1998).

A partir da dose inseminante de $6 \times 10^{5}$ espermatozoides.ovócito ${ }^{-1}$ (Figura 1), as taxas de fertilização foram completamente prejudicadas, com $0 \%$ de fertilização. A relação quadrática entre a taxa de fertilização e a dose inseminante observada neste experimento (Figura 1) confirma os relatos de Tevedt et al. (2001) de que altas taxas de fertilização podem ser alcançadas dentro de um amplo intervalo de doses inseminantes. Para o bagre-africano (Clarias gariepinus), Rurangwa et al. (1998) demonstraram que altas e baixas doses inseminantes afetam negativamente as taxas de fertilização artificial de ovócitos.

De acordo com Rurangwa et al. (2004), as taxas de fertilização podem sofrer influência de diversos fatores, como o número de espermatozoides por ovócito, o tempo de contato entre os gametas e o protocolo de fertilização. As relações adequadas entre o número de espermatozoides.ovócito ${ }^{-1}$ podem variar entre espécies, uma vez que as relações encontradas neste experimento para o dourado foram inferiores às observadas por Bombardelli et al. (2006a) para o jundiá (Rhamdia quelen), de aproximadamente $9 \times 10^{4}$ espermatozoides.ovócito ${ }^{-1}$ (Figura 1 ).

No entanto o comportamento dessas variáveis entre as espécies não é constante, pois Bombardelli et al. (2006a) verificaram que, a partir da dose inseminante ideal para o

Tabela 1 - Parâmetros corporais de machos e fêmeas e parâmetros seminais de dourado

\begin{tabular}{|c|c|c|}
\hline Item & Ensaio $1^{\mathrm{a}}$ & Ensaio $2^{b}$ \\
\hline Peso dos machos (g) & $720,00 \pm 239,44$ & $1040,00 \pm 167,33$ \\
\hline Peso das fêmeas (g) & $1350,00 \pm 1247,00$ & - \\
\hline Comprimento total dos machos $(\mathrm{cm})$ & $40,2 \pm 4,59$ & $47,2 \pm 1,75$ \\
\hline Comprimento total das fêmeas $(\mathrm{cm})$ & $44,30 \pm 13,34$ & - \\
\hline Volume de sêmen liberado/reprodutor (mL) & $7,24 \pm 5,18$ & $12,32 \pm 1,90$ \\
\hline Produção seminal relativa (mL.kg de reprodutor ${ }^{-1}$ ) & $9,34 \pm 4,54$ & $12,12 \pm 2,75$ \\
\hline Concentração espermática, espermatozoides por mL de sêmen $\left(\times 10^{9}\right)$ & 7,52 & 7,58 \\
\hline Índice de sobrevivência (\%) & $91,95 \pm$ & 96,38 \\
\hline Duração da motilidade espermática (s) & $29,87 \pm 2,03$ & $38,11 \pm 0,90$ \\
\hline
\end{tabular}

a Ensaio 1 = ensaio de determinação da dose inseminante aplicada em ovócitos.

${ }^{\mathrm{b}}$ Ensaio 2 = ensaio do tempo de duração da motilidade espermática em diferentes diluições. 
jundiá, os índices de fertilização alcançaram um platô, no qual as taxas de fertilização permanecem constantes com o aumento do número de espermatozoides.ovócito-1. Resultados semelhantes foram evidenciados para a piabanha (Brycon insignis) por Shimoda et al. (2007), que recomendaam dose ótima de 314.418 espermatozoides. ovócito ${ }^{-1}$.

Outros autores aplicam doses inseminantes a partir de aumentos constantes do número de espermatozoides em relação ao volume de solução ativadora. Casselman et al. (2006) observaram para o "walleye" (Sander vitreus) crescentes taxas de fertilização com o aumento do número de espermatozoides.mL de solução ativadora ${ }^{-1}$. Esses autores sugeriram o uso de $5 \times 10^{4}$ espermatozoides.mL de água $^{-1}$ em aproximadamente 100 ovócitos de "walleye" (Sander vitreus). Segundo Casselman et al. (2006), as baixas taxas de fertilização alcançadas em baixas relações espermatozoides:mL de água, podem ter sido provocadas pela alta diluição entre os espermatozoides e os ovócitos, uma vez que essas diluições não proporcionaram o encontro dos gametas, devido ao baixo tempo de motilidade dos espermatozoides. Resultados semelhantes foram evidenciados por Hoysak \& Liley (2001) para o "sockeye salmon”, com melhores taxas de fertilização no emprego de 50-100 $\mu \mathrm{L}$ de sêmen em $500 \mathrm{~mL}$ de solução ativadora e $20 \mathrm{~mL}$ de ovócitos. O turbot (Scophthalmus maximus) necessita de apenas 6.000 espermatozoides.ovócito-1 ${ }^{-1}$ para garantir bons índices de fertilização (Suquet et al., 1995).

Algumas características, como o tamanho dos ovócitos, a distância de natação dos espermatozoides e o tempo de duração da motilidade espermática e do fechamento da micrópila, são determinantes para a aplicação destas doses (Billard \& Cosson, 1992; Suquet et al., 1995). Além disso, diferem bruscamente entre as espécies de peixes teleósteos (Godinho, 2007).

A qualidade dos gametas femininos (Suquet et al., 1995) e masculinos (Rinchard et al., 2005) utilizados no processo de fertilização artificial, é importante na aplicação das doses inseminantes. A utilização de gametas que não se apresentam em perfeitas condições para a realização da fertilização artificial revela a necessidade de aplicações de doses inseminantes superiores (Suquet et al., 1995; Rinchard et al., 2005).

A distância percorrida pelos espermatozoides, juntamente com o diâmetro do ovo é significante na determinação da dose inseminante (Suquet et al., 1995), uma vez que os ovócitos apresentam apenas um ponto de penetração, denominado micrópila, e, como os espermatozoides necessitam circundar os ovócitos para encontrá-la, é necessário grande número de espermatozoides no meio fertilizante (Rurangwa et al., 1998) em relação ao diâmetro ovocitário.

Outros fatores podem influenciar as taxas de fertilização, a exemplo da diluição do material fertilizante (Cherenguini et al., 1999).

Houve efeito da diluição do material fertilizante sobre a duração da motilidade espermática, com relação diretamente proporcional $(\mathrm{P}<0,05)$ (Figura 2$)$.

De acordo com Billard \& Cosson (1992), a relação volume de sêmen:volume de água é um fator limitante na

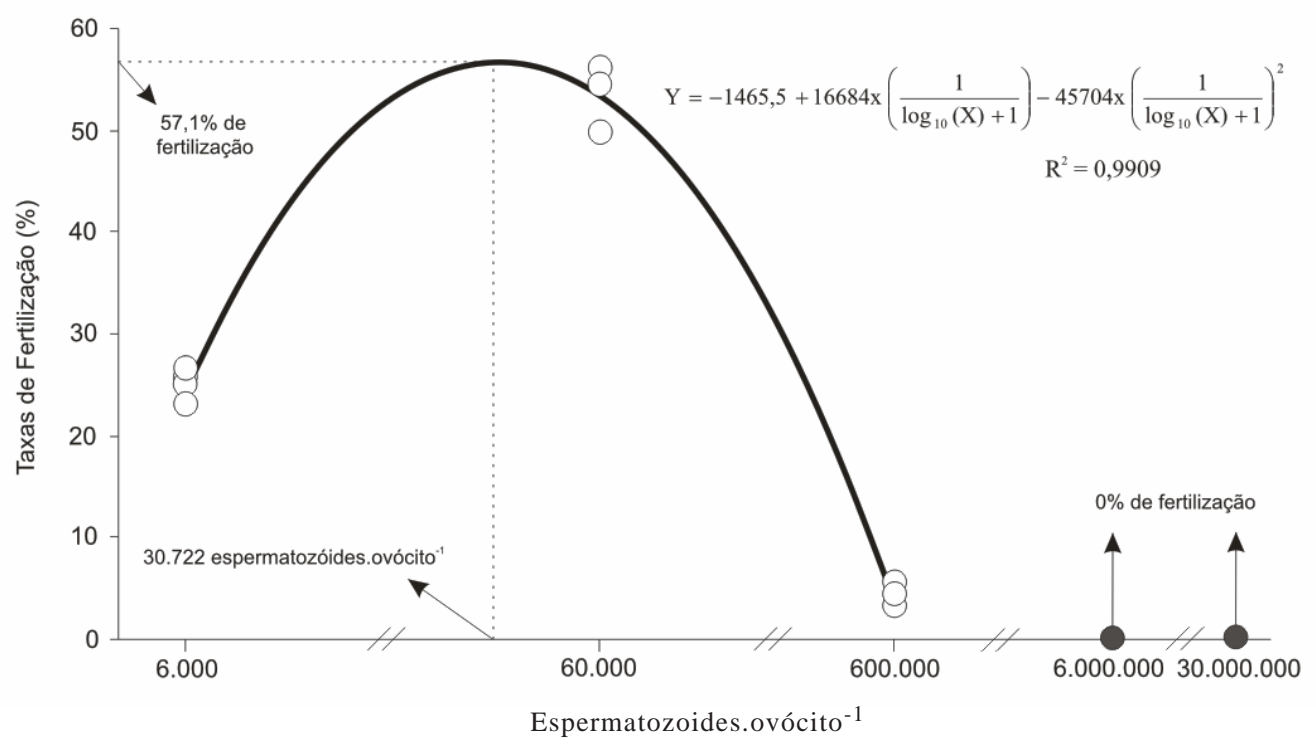

Figura 1 - Taxas de fertilização artificial de ovócitos de dourado (S. brasiliensis) fertilizados artificialmente com diferentes relações espermatozoides/ovócito. 
caracterização da motilidade espermática e a concentração espermática no meio inseminante e o volume do diluente são os principais desencadeadores da ativação dos espermatozoides. Isso porque, em peixes teleósteos de água doce, a ativação espermática é promovida pela redução da concentração osmótica do meio em que o sêmen estiver diluído (Billard, et al. 1995). Neste sentido alguns autores sugeriram que estas diluições não devem ser inferiores a 1:1000, pois não garantem a eficiente quebra da viscosidade seminal, afetando assim, a completa ativação dos espermatozoides (Billard \& Cosson, 1992).

Associadas ao processo de diluição do meio inseminante, a motilidade espermática pode ser afetada pela composição da solução ativadora e do plasma seminal (Emri et al., 1998). As principais variáveis afetadas neste caso podem ser a viscosidade (Billard \& Cosson, 1992), o pH (Alavi \& Cosson, 2005), a concentração dos íons $\mathrm{K}^{+}$, $\mathrm{Na}^{+}, \mathrm{Ca}^{2+}, \mathrm{Mg}^{2+}$ (Alavi \& Cosson, 2006), a osmolaridade (Alavi et al., 2007), a atividade proteica (Fauvel et al., 1999), os níveis de lipídeos totais, as atividades enzimáticas e os níveis de ATP e NADH espermáticas (Lahnsteiner et al., 1998). Esses fatores, correlacionados corretamente, aumentam a duração da motilidade espermática e consequentemente a capacidade de fertilização (Cosson, 2004).

A diluição do material fertilizante também tem duas importantes implicações sobre as taxas de fertilização: o uso de pouca água como solução ativadora, além de comprometer a ativação espermática, pode proporcionar um meio inadequado para o encontro dos gametas
(Chereguini et al., 1999); e o excessivo volume de água pode diluir excessivamente o meio, impedindo o espermatozoide de alcançar a micrópila durante o curto período de tempo de ativação que adquirem (Chereguini et al., 1999).

Esses resultados (Figura 1) confirmam as afirmativas de Chereguini et al. (1999), pois, em reduzidas doses inseminantes, a perda da eficiência da fertilização pode ter sido consequênica da dispersão dos gametas.

Por outro lado, doses inseminantes superiores a 30.722 espermatozoide.ovócito ${ }^{-1}$ afetaram negativamente as taxas de fertilização, a ponto de proporcionar resultados nulos para as doses de $6 \times 10^{6}$ e $3 \times 10^{7}$ espermatozoides.ovócito ${ }^{-1}$ (Figura 1). Ainda, além de exercer influência deletéria no tempo de motilidade espermática (Figura 2), a redução da diluição do material fertilizante possivelmente afetou de modo negativo as taxas de fertilização dos ovócitos do dourado.

Alguns autores sugerem que os prejuízos causados aos espermatozoides de alguns peixes teleósteos de água doce pelas reduzidas diluições do meio inseminante podem estar relacionados ao fato de o aumento da demanda energética e da atividade enzimática exercida durante a movimentação, gerar possíveis condições anóxicas no meio diluente (Lahnsteiner et al., 1998). Outros autores sugerem ainda que a diluição do meio inseminante pode beneficiar o processo de fertilização, em decorrência das possíveis melhorias no consumo de oxigênio pelos gametas e redução da oxidação do sêmen (Weingartner \& Zaniboni-Filho, 2007).

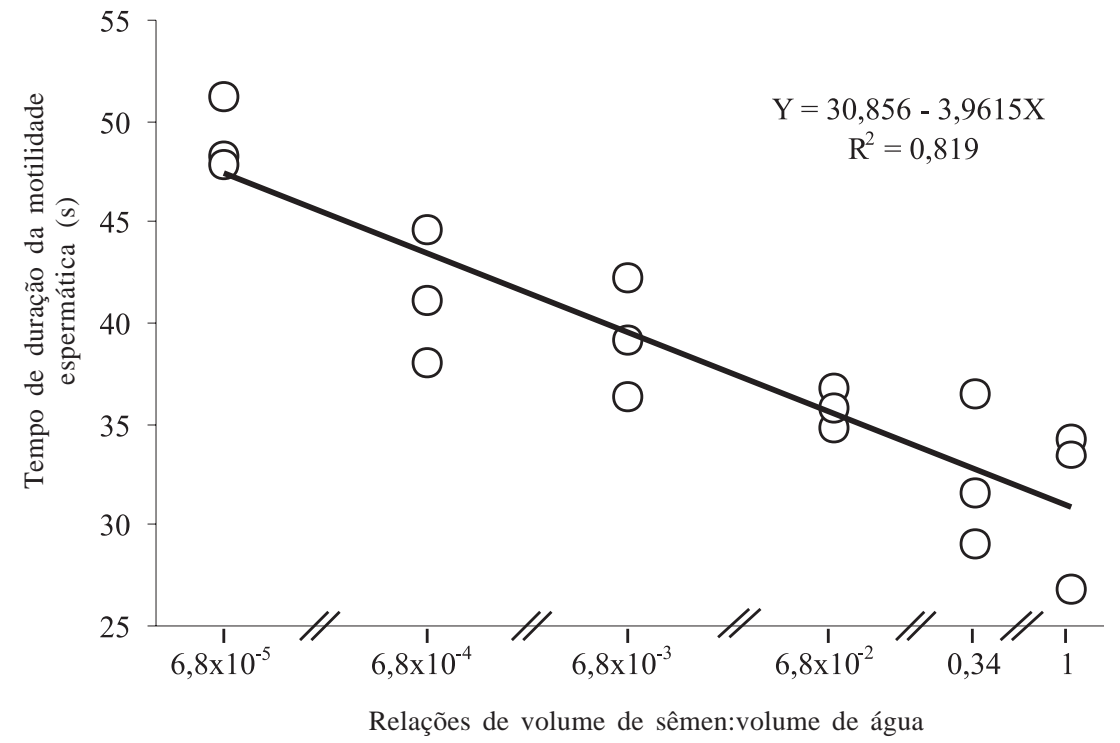

Figura 2 - Duração da motilidade espermática dos espermatozoides de dourado (S. brasiliensis) submetidos à ativação sob diferentes relações de diluição entre o volume de sêmen e o volume de água. 
Novos estudos relacionados aos métodos empregados na fertilização artificial, especialmente aqueles que influenciam na relação espermatozoide:ovócito devem ser realizados. Esses novos trabalhos poderão subsidiar novas pesquisas, além de elucidar o comportamento e/ou a interação de variáveis determinantes do sucesso da reprodução artificial.

\section{Conclusões}

Melhores taxas de fertilização dos ovócitos de dourado (Salminus brasiliensis) podem ser alcançadas com o uso de 0,44 mL de sêmen em 100 mL de ovócitos não-hidratados e ativação em $1.250 \mathrm{~mL}$ de água.

\section{Literatura Citada}

ALAVI, S.M.H.; COSSON, J. Sperm motility in fishes. (I) Efects of temperature and $\mathrm{pH}$ : a review. Cell Biology International, v.29, p.101-110, 2005

ALAVI, S.M.H.; COSSON, J. Sperm motility in fishes. (II) Effects of ions and osmolality: A review. Cell Biology International, v.30, p.1-14, 2006.

ALAVI, S.M.H.; RODINA, M.; POLICAR, T. et al. Semen of Perca fluviatilis L.: Sperm volume and density, seminal plasma indices and effects of dilution ratio, ions and osmolality on sperm motility. Theriogenology, n.68, p.276-283, 2007.

ANDRADE-TALMELLI, E.F.; KAVAMOTO, E.T.; FENERICHVERANI, N. Características seminais da piabanha, Brycon insignis (Steindachner, 1876), após estimulação hormonal. Boletim do Instituto de Pesca, v.27, n.2, p.149-154, 2001.

BASTARDO, H.; GUEDEZ C.; LEÓN, M. Características del semen de trucha arco-iris de diferentes edades, bajo condiciones de cultivo en Mérida, Venezuela. Zootecnia Tropical, v.22, n.3, p.277-288, 2004.

BILLARD, R.; COSSON, J.; CRIM, L.W. et al. Sperm physiology and quality. In: BROMAGE, N.R.; ROBERTS, R.J. (Eds.) Broodstock management and egg and larval quality. London: Blackwell Science, 1995. p.25-52.

BILLARD, R.; COSSON, M.P. Some problems related to the assessment of sperm motility in freshwater fish. The Journal of Experimental Zoology, v.261, p.22-31, 1992.

BOMBARDELLI R.A.; MÖRSCHBÄCHER, E.F.; CAMPAGNOLO, R. et al. Dose inseminante para fertilização artificial de ovócitos de jundiá Rhamdia quelen (Quoy \& Gaimardm, 1824). Revista Brasileira de Zootecnia, v.35, n.4, p.1251-1257, 2006a.

BOMBARDELLI, R.A.; SYPERREK, M.A.; SANCHES, E.A. Hormônio liberador de gonadotrofinas em peixes: aspectos básicos e suas aplicações. Arquivos de ciências Veterinárias e Zoologia da UNIPAR, v.9, n.1, p.59-65, 2006b.

BORGES, A.; SIQUEIRA, D.R.; JURINITZ1, D.F. et al. Biochemical composition of seminal plasma and annual variations in semen characteristics of jundia' Rhamdia quelen (Quoy and Gaimard, Pimelodidae). Fish Physiology and Biochemistry, v.31, p.45-53, 2005.

CAROLSFELD, J.; GODINHO H.P.; ZANIBONI FILHO E. et al. Cryopreservation of sperm in Brazilian migratory fish conservation. Journal of Fish Biology, v.63, p.472-489, 2003.

CASSELMEN, S.; SCHUTE-HOSTEDDE, A.I.; MONTGOMERIE, R. Sperm quality influences male fertilization success in walley (Sander vitreus). Canadian Journal Aquatic Science, v.63, p.2119-2125, 2006.

CHEREGUINI, O.; DE LA BANDA, I.G.; RASINES, I. et al.Artificial fertilization in turbot, Scopothalmus maximus, (L.): different methods and determination of the optimal sperm-egg ratio. Aquaculture Research, v.30, p.319-324, 1999.

COLÉGIO BRASILEIRO DE REPRODUÇÃO ANIMAL - CBRA. Manual para exames andrológicos e avaliação de sêmen animal. 2.ed. Belo Horizonte: Colégio Brasileiro de Reprodução Animal, 1998. 49p

COSSON, J. The ionic and osmotic factors controlling motility of fish spermatozoa Aquaculture International, v.12, p.69-85, 2004.

DENNISTON. R.S.; MICHELET, S.; GODKE, R.A. Principles of Cryopreservation. In: TIERSCH, T.R.; MAZIK, P.M. (Eds.) Cryopreservation in Aquatic Species. Morgantown: The World Aquaculture Society, 2000, p.59-74.

EMRI, M.; MÁRIÁN, T.; TRÓN, L. et al. Temperature adaptation changes íon concentrations in spermatozoa and seminal plasma of common carp without affeting sperm motility. Aquaculture, v.167, p.85-94, 1998.

FAUVEL, C.; SAVOYE, O.; DREANNO, C. et al. Characteristics of sperm of captive seabass in relation to its fertilization potential. Journal of Fish Biology, v.54, p.356-369, 1999.

FERREIRA, A.A.; NUÑER, A.P.O.; LUZ, R.K. et al. Avaliação qualitativa e quantitativa do sêmen de jundiá, Rhamdia quelen. Boletim do Instituto de Pesca, v.27, n.1, p.57-60, 2001.

FOGLI DA SILVEIRA, W.; KAVAMOTO, E.T.; RIGOLINO, M.G. et al. Fertilidade do sêmen de truta arco-íris, Salmo irideus gibbons, em diferentes concentrações de espermatozoides por óvulo. Boletim do Instituto de Pesca, v.15, n.1, p.51-54, 1988.

FOGLI DA SILVEIRA, W.; KAVAMOTO, E.T.; CESTAROLLI, M.A. et al. Avaliação espermática, preservação criogênica e fertilidade do sêmen do pacu, Piaractus mesopotamicus (Holmberg, 1887), proveniente de reprodução induzida. Boletim do Instituto de Pesca, v.17, n.único, p.1-13, 1990.

FROESE, R.; PAULY, D. [2007]. FishBase: World Wide Web electronic publication. Disponível em: <http://www.fishbase.org>. Acesso em: 22/6/2007.

GODINHO, H.P. Estratégias reprodutivas de peixes aplicadas à aqüicultura: bases para o desenvolvimento de tecnologias de produção. Revista Brasileira de Reprodução Animal, v.31, n.3, p.351-360, 2007.

HILBIG, C.C; BOMBARDELLI, R.A.; SANCHES, E.A. et al. Efeito do chumbo sobre a fertilização artificial e incubação de ovos de jundiá cinza (Rhamdia quelen). Acta Scientiarum. Animal Sciences, v.30, n.2, p.217-224, 2008.

HOYSAK, D.J.; LILEY, N.R. Fertilization dynamics in sockeye salmon and a comparison of sperm from alternative male phenotypes. Journal of Fish Biology, v.58, p.1286-1300, 2001.

KAVAMOTO, E.T.; FOGLI DA SILVEIRA, W. Características físicas, químicas e microscópicas do sêmen do bagre, Rhamdia hilarii (Valenciennes, 1840) em condições de campo. Boletim do Instituto de Pesca, v.13, p.95-100, 1986.

KAVAMOTO, E.T.; MAINARDES-PINTO, C.S.R.; ANDRADE TALMELLI, E.F.; et al. Produção espermática do curimbatá Prochilodus scrofa Steindachner, 1881. Boletim do Instituto de Pesca, v.24, n.único, p.73-78, 1997.

LAHNSTEINER, F.; BERGER, B.; WEISMANN, T. Effects of media, fertilization technique, extender, straw volume, and sperm to egg ratio on hatchability of cyprinid embryos, using cryopreserved semen. Theriogenology, v.60, p.829-841, 2003.

LAHNSTEINER, F.; BERGER, B.; WEISMANN, T. et al. Determination of semen quality of the rainbow trout, Oncorhynchus mykiss, by sperm motility, seminal plasma parameters, and spermatozoal metabolism. Aquaculture, v.163, p.163-181, 1998.

LUZ, R.K.; FERREIRA, A.A.; REYNALTE-TAJATE, D.A. et al. Avaliação qualitativa e quantitativa do sêmen do suruvi, Steindachneridion scripta (pimelodidae). Boletim do Instituto de Pesca, v.27, n.1, p.39-42, 2001.

MARIA, A.N.; MURGAS, L.D.S.; BARBOSA SILVA, M.O. et al. Influência da adição de iodeto de potássio e citrato de sódio na 
qualidade do sêmen de pacu (Piaractus mesopotamicus Holmberg, 1887). Ciência e Agrotécnologia, v.28, n.1, p.191-194, 2004.

MARQUES, S.; GODINHO, H.P. Short-term cold storage of sperm from six neotropical characiformes fishes. Brazilian Archives of Biology and Technology, v.47, n.5. p.799-804, 2004.

MURGAS, L.D.S.; FRANCISCATTO, R.T.; SANTOS, A.G.O. Avaliação espermática pós-descongelamento em piracanjuba Bbrycon orbignyanus, Vallenciennes, 1849). Revista Brasileira de Zootecnia, v.32, n.6, p.1810-1814, 2003 (supl. 2).

MURGAS, L.D.S.; MILIORINI, A.B.; FRANCISCATTO, R.T. et al. Viabilidade espermática do sêmen de Piracanjuba (Brycon orbignyanus) resfriado a $4^{\circ} \mathrm{C}$. Revista Brasileira de Zootecnia, v.33, n.6, p.1361-1365, 2004.

MURGAS, L.D.S.; MILIORINI, A.B.; FREITAS, R.T.F. et al. Criopreservação do sêmen de curimba (Prochilodus lineatus) mediante adiçãode diferentes diluidores, ativadores e crioprotetores. Revista Brasileira de Zootecnia, v.36, n.3, p.526-531, 2007.

NAKATANI, K.; AGOSTINHO, A.A.; BAUMGARTNER, G. et al. Ovos e larvas de peixes de água doce. Maringá: EDUEM, 2001. 378p.

NINHAUS-SILVEIRA, A.; FORESTI, F.; VERÍSSIMO-SILVEIRA, R. et al. Seminal analysis, cryogenic preservation, and fertility in matrinxã fish, Brycon cephalus (Günther, 1869). Brazilian Archives of Biology and Technology, an International Journal, v.49, n.4, p.651-659, 2006.

RINCHARD, J.; DABROWSKI, K.; VAN TASSELL, J.J. et al. Optimization of fertilization success in Sander vitreus is influenced by the sperm: egg ratio and ova storage, Journal of Fish Biology, v.67, p.1157-1161, 2005.

RIZZO, E.; GODINHO, H.P.; SATO, Y. Short-term storage of oocytes from the neotropical teleost fish Prochilodus marggravii. Theriogenology, v.60, p.1059-1070, 2003.

RURANGWA, E.; KIME, D.E.; OLLEVIER, F. et al. The measurement of sperm motility and factors affecting sperm quality in cultured fish. Aquaculture, v.234, p.1-28, 2004.

RURANGWA, E.; ROELANTS, I.; HUYSKENS, G. et al. The minimum effective spermatozoa:egg ratio for artificial insemination and the effects of mercury on sperm motility and fertilization ability in (Clarias gariepinus). Journal of Fish Biology, v.53, p.402-413, 1998.

SHIMODA, E.; ANDRADE, D.R.; VIDAL JR., M.V. et al. Determinação da razão ótima de espermatozoides por ovócitos de piabanha Brycon insignis (pisces - characidae). Arquivos Brasileiros de Medicina Veterinária e Zootecnia, v.59, n.4, p.877-882, 2007.

SOUZA, B.E.S.; SANCHES, E.A.; BAGGIO, D.M.; Interação entre a relação de espermatozoide.ovócito-1 e o volume de água empregados na fertilização artificial de ovócitos de curimbatá (Prochilodus lineatus) In: CONGRESSO BRASILEIRO DE
PRODUÇÃO DE PEIXES NATIVOS DE ÁGUA DOCE, 1., 2007, Dourados. Anais... Dourados: Embrapa [2007]. (CD-ROM).

STOECKEL, J.N.; A method for viewig the germinal vesicle in oocytes of commercial catfishes. North American Journal of Aquaculture, v.62, p.240-247, 2000.

STREIT JR., D.P.; RIBEIRO, R.P.; MORAES, G.V. et al. Características qualitativas do sêmen de pacu (Piaractus mesopotamicus) após indução hormonal. Bioscience Journal, v.22, n.3, p.119-125, 2006.

STREIT JR., D.P.; MORAES, G.V.; RIBEIRO, R.P.R. et al. Estudo comparativo da indução hormonal da espermiação em piavuçu (Leporinus macrocephalus) com extrato de hipófise de frango, coelho e carpa. Acta Scientiarum. Animal Sciences, v.25, n.2, p.261-266, 2003.

STREIT JR., D.P.; MORAES, G.V.; RIBEIRO, R.P. et al. Comparação do sêmen de Curimbá ( Prochilodus lineatus) induzido por extrato de hipófise de frango, coelho ou carpa. Brazilian Journal of Veterinary and Animal Science, v.41, p.147-153, 2004a.

STREIT JR., D.P.; MORAES, G.V.; RIBEIRO, R.P. et al. Avaliação de diferentes técnicas para coloração de sêmen de peixes. Arquivos de Ciências Veterinárias e Zoologia da UNIPAR, v.7, n.2, p.157-162, 2004b.

SUQUET, M.; BILLARD, R.; COSSON, J.C. et al. Artificial insemination in turbot (Scophthalmus maximus): determination of the optimal sperm to egg ratio and time of gamete contact. Aquaculture, v.133, p.83-90, 1995.

TVEDT, H.B.; BENFEY, T.J.; MARTIN-ROBICHAUD, D.J. et al. The relationship between sperm density, spermatocrit, sperm motility and fertilization success in Atlantic halibut, hippoglossus hippoglossus. Aquaculture, v.194, p.191-200, 2001.

UNIVERSIDADE FEDERAL DE VIÇOSA - UFV. Sistema para análises estatísticas e genéticas - SAEG. Versão 7,1. Viçosa, MG: 1997. 150p. (Manual do usuário).

WEINGARTNER, M.; ZANIBONI FILHO Dourado In: BALDISSEROTTO, B.; GOMES L.C. (Eds.) Espécies nativas para a piscicultura no Brasil. Santa Maria: Editora UFSM, 2005. p.257-286

WEINGARTNER, M.; ZANIBONI FILHO, E. Efeito do curto período de estocagem dos ovócitos e tempo de enxágüe da água de ativação dos gametas na reprodução de dourado Salminus brasiliensis In: CONGRESSO BRASILEIRO DE PRODUÇÃO DE PEIXES NATIVOS DE ÁGUA DOCE, 1., 2007, Dourados. Anais... Dourados: Embrapa [2007]. (CD-ROM).

WIRTZ, S.; STEINMANN, P. Sperm characteristics in perch Perca fluviatilis L. Journal of Fish Biology, v.68, p.1896-1902, 2006.

WOYNAROVICH, E.; HORVATH, L. Propagação artificial de peixes de águas tropicais: manual de extensão. Trad. Vera Lucia Mixtra Chama. Brasília: Escopo, 1983. 220p.

ZANIBONI FILHO, E.; WEINGARTNER, M. Técnicas de indução da reprodução de peixes migradores. Revista Brasileira de Reprodução Animal, v.31, n.3, p.367-373, 2007. 